\title{
Recognising the Rising Stars of Separation Science
}

\author{
Brett Paull ${ }^{1}$
}

Published online: 8 January 2019

(c) Springer-Verlag GmbH Germany, part of Springer Nature 2019

It has been almost 2 years ago since Chromatographia published its last special issue dedicated to Young Investigators in Separation Science [1]. At the time of writing, the submissions making up this special issue, from the eight contributing young authors [2-9], have collectively amassed some 4520 downloads, highlighting the level of interest in the analytical science community for the great work our younger colleagues, junior academics and scientists are undertaking. Therefore, to continue our mission to highlight and celebrate achievements of the next generation of separation science leaders, and mark their achievements to-date, we present this current special issue dedicated to the 'Rising Stars of Separation Science', which is also perfectly timed to coincide with the 50-year anniversary celebrations of Chromatographia.

To be able to introduce this special issue to you is indeed a privilege. The future direction of separation science, and the role it will play across the diverse fields of fundamental and applied science and technology, will be determined by our rising stars and emerging leaders. So here we have our long-established pillar of the chromatography society, that is our journal Chromatographia, now entering its second half-century, recognising the achievements of some of those who, whilst not born at the time of its launch, will hopefully continue to fill its pages for many years to come.

This year's special issue has invited contributions from nine early career researchers, who were selected by the Editors, after having caught their attention as rising stars in the field of separation science. This current collection includes cutting edge original research papers discussing superficially

Published in the topical collection Rising Stars in Separation Science, as part of Chromatographia's 50th Anniversary Commemorative Issue.

Brett Paull

brett.paull@utas.edu.au

1 Australian Centre for Research on Separation Science (ACROSS), School of Natural Sciences, University of Tasmania, Hobart, Australia porous particles and ultra-high pressure liquid chromatography in pharmaceutical separations [10], ultra-high performance supercritical fluid chromatography of dietary supplements [11], the impact of detectors on band-broadening in ultra-high performance methods [12], and multi-channel selective wavelength detection of benzo(a)pyrene isomers [13]. In addition, the collection includes substantial comprehensive critical review papers on topics as diverse as metal-organic frameworks in separation science [14], multidimension gas chromatography of essential oils $[15,16]$, methods for purification and characterisation of extracellular vesicles [17], immobilized enzyme reactors [18], and morphologically ordered and 3D-printed stationary phases [19].

We hope you find inspiration from both the contents of the works and the authors' themselves, from whom I am sure you will be hearing much more in the near future!

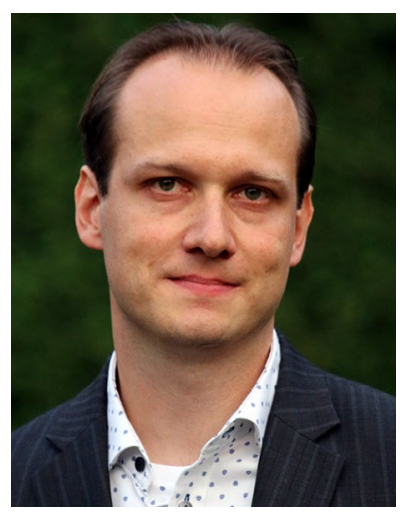

Ken Broeckhoven has been an associate professor at the Vrije Universiteit Brussel (VUB) in Belgium since February 2017, in the departments of Chemical Engineering and Bioengineering Sciences. Before that, at the age of 28 , he was appointed as tenure track research professor at the VUB in both the Faculty of Sciences and Bioengineering Sciences and the Faculty of Engineering, the youngest person ever to receive this position. He teaches courses on Chemical Process Technology, Modelling of Biomedical Systems, Heat and Mass Transfer and Technology projects on Environmental Engineering. His research focuses on fundamental aspects of chromatography and the optimization aspects of separation performance in both liquid and supercritical fluid chromatography. He is author of more than 60 research papers with more than 800 citations and presented over 40 oral presentations at international conferences. He was part of the "Top 40 Under 40 " by The 
Analytical Scientist in both editions (2014 and 2018) and the recipient of the LCGC magazine's "Emerging leader in chromatography" award in 2019. During his Ph.D., his poster was ranked nr. 1 at the Best Poster Award competition at HPLC2008 in Boston (MA, USA) and afterwards his Ph.D. students obtained numerous poster awards at different international conferences. He is also part of the organizing and scientific committee of the biennial HTC-conference series (Hyphenated Techniques in Chromatography) and member of the ChiMiC consortium, grouping 5 leading groups in chromatographic techniques in Belgium. Since 2014, he has been a member of the editorial board of Journal of Pharmaceutical Analysis and since 2018 of the advisory editorial board of Journal of Chromatography.

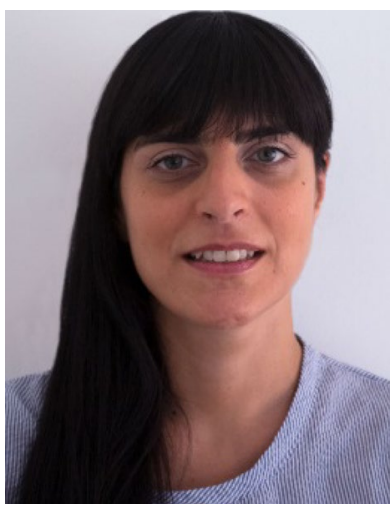

Angela De Simone graduated in Chemistry and Pharmaceutical Technology in 2006 at the University of Bologna and in 2010 she defended her Ph.D. thesis titled "A Multi-Methodological Approach for BioRecognition Study". From 2011 to 2012 she had a position as post doc-junior at Italian Institute of Technology, Genova. Since September 2012 she has worked as research fellow at the Department for Life Quality Studies, University of Bologna. In 2015-2016 she spent 6 months as visiting researcher at Ludwig Maxmilians University, Munich, Germany, carrying out a research project aimed at the development of a MS binding assay study applied on h-DAT, h-NET and h-SERT transporters. Her research lines are mostly connected to the individuation of bioactive molecules for the prevention and the treatment of neurodegenerative disease, in particular of Alzheimer's Disease. For this purpose, her studies are focused on the development of new analytical approaches and on the use of classical and multiwells spectroscopic methods (UV-Vis, fluorescence, luminescence) for the evaluation of compounds' activity against beta-site amyloid precursor protein cleaving enzyme 1 (BACE1), glycogen synthase kinase 3 beta (GSK-3 $\beta$ ) and beta amyloid aggregation. The aim is to characterize multi-potent compounds able to simultaneously act on the production and aggregation of amyloid-beta peptide and on the formation of neurofibrillary tangles as critical points of the pathology. In this context, fast and automated analytical techniques, based on immobilized enzymes reactors, have been developed and used to screen and characterize new ligands for BACE1 enzyme. Moreover the new developed methods based on UHPLC and ESI-Q-ToF methodologies are adopted for the direct evaluation of the inhibitory potency and mechanism of action of new compounds against GSK-3 $\beta$. The research is also focused on the development of multi-methodological approach for bio-recognition study involving MS, HPLC, GC-MS, circular dichroism, fluorescence and optical biosensor technologies.

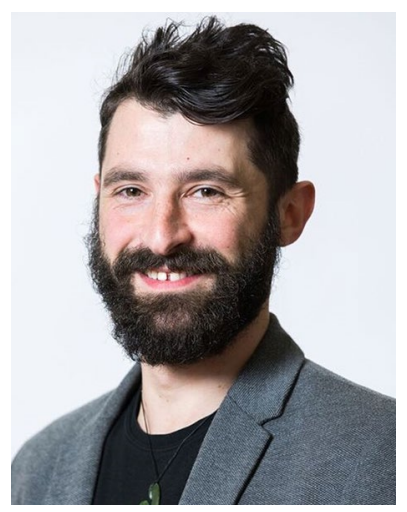

Simone Dimartino is a senior lecturer at the Institute for Bioengineering at the University of Edinburgh, UK. He received his Ph.D. from the University of Bologna (Italy, 2009) followed by a PostDoc at the University of Canterbury (New Zealand). He has been always working on the development of new stationary phases for chromatography, spanning from membranes to monoliths to fibre-based media. He now employs 3D printing methods for the fabrication of chromatography media with perfectly ordered morphology, with specific focus on the design of novel three-dimensional lattices and the development of materials compatible with both 3D printers and chromatographic operations. Dr. Dimartino's research group is currently transferring methods developed in chromatography to other relevant operations in the biotechnology industry (e.g. biocatalysis and bioreactors) and in chemical engineering $\left(\mathrm{CO}_{2}\right.$ capture). The novelty and quality of this research have been recognised with a number of international awards, including three best poster awards in 3 continuous years at the PREP conference series, and the Csaba Horvath Young Scientist Award at HPLC 2016. Dr. Dimartino is co-author of over 30 papers in international journals. He also is in the editorial board of Scientific Reports, open access journal from the publishers of Nature.

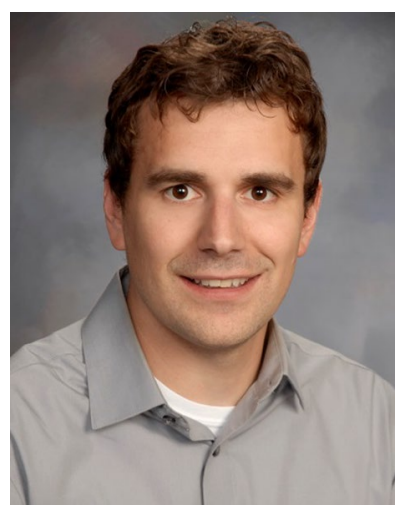

James Grinias has spent the past decade researching the fundamentals of liquid-phase separations in capillary and microfluidic columns as well as applications in neuroscience, molecular physiology, and pharmaceutical fields. He also studies the use of new technology to enhance educational outcomes in the undergraduate analytical chemistry curriculum. Dr. Grinias received his bachelor's degree in Chemistry from Eastern Michigan University and his doctoral degree in Analytical Chemistry from the University of North Carolina at Chapel Hill. He also completed 
a postdoctoral research fellowship at University of Michigan. Dr. Grinias has received many honors for his work, including a National Science Foundation Graduate Research fellowship, National Institutes of Health National Research Service Award postdoctoral fellowship, the 2013 Csaba Horvath Young Scientist Award, and the 2017 Eastern Michigan University Young Alumnus of the Year Award. He was also recently named in the "Top 40 Under 40" Power List by The Analytical Scientist. Since 2010, Dr. Grinias has been a member of the American Chemical Society and its Chromatography and Separations Chemistry subcommittee. He is an executive committee member of the Chromatography Forum of Delaware Valley, has helped organize the 2016 and 2018 HPLC conferences, and regularly serves as a reviewer for several separation-related journals.

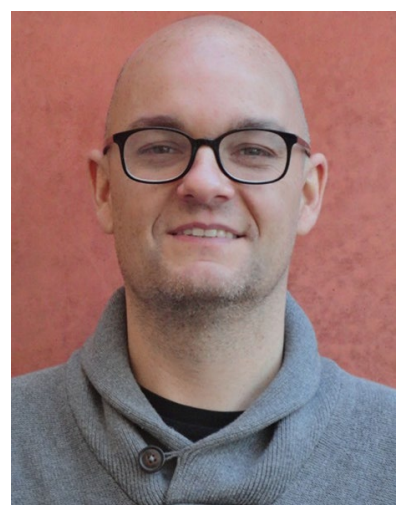

Fernando Maya is a lecturer in chemistry at the University of Tasmania (Australia), where he is also an academic member of the Australian Centre for Research on Separation Science (ACROSS). He received his $\mathrm{Ph} . \mathrm{D}$. in Chemistry from the University of the Balearic Islands (UIB, Spain, 2011) under the supervision of Víctor Cerdà and José M. Estela. During his Ph.D., he spent 3 months at the University of Hull (UK) working with Gillian M. Greenway, and 3.5 months at the Lawrence Berkeley National Laboratory (LBNL, USA) working with Frantisek Svec. Afterwards, he returned to the LBNL for 24 months as a Fulbright Postdoctoral Fellow. In 2014, he returned to the UIB as a postdoctoral researcher and adjunct lecturer. He was invited as researcher at the University of Copenhagen (2011), and Fulbright Occasional Lecturer at the University of Minnesota Morris (2013). In 2017, he received the FIA Award for Young Researchers by the Japanese Association for Flow Injection Analysis (JAFIA), a Juan de la Cierva Fellowship (Government of Spain), and joined the International Editorial Board of Journal of Separation Science. $\mathrm{He}$ (co-)authored more than 50 peer-reviewed publications. His research interests are directed to the synthesis of novel porous materials for sample preparation and chromatographic separation, analytical method automation, and the design of novel 3D-printed devices for analytical applications.

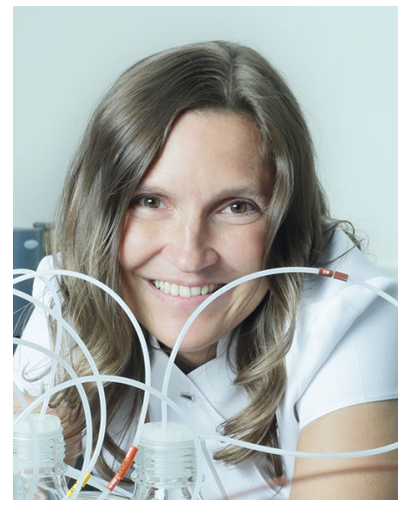

Lucie Nováková has been an Associate Professor in Analytical Chemistry at the Charles University, Faculty of Pharmacy in Hradec Králové, Department of Analytical Chemistry, Czech Republic since 2011. She received her Ph.D. from Pharmaceutical Analysis at the same university in 2005. Her research is oriented towards separation techniques, namely ultra-high performance liquid chromatography, supercritical fluid chromatography, and their coupling to mass spectrometry. She is involved in a wide scope of research projects focused on pharmaceutical analysis, doping control, plant analysis, and bioanalytical methods. An important part of her research lays also in the sample preparation step, where the focus is put on the current trends enabling facilitation, miniaturization and reduction of time and sample requirements. She extended her scientific experience during fellowships at world-recognized universities, such as University of Geneva and Vrije Universiteit Brussel, beyond others. She authored two books on HPLC theory and practice and 9 book chapters. She published over 95 peer-reviewed scientific articles and review papers with more than 2600 citations and h-index of 29. She is also widely involved in teaching and education activities, such as HPLC and SFC training courses, seminars and conferences. Currently, she is a principal team manager of the STARSS project.

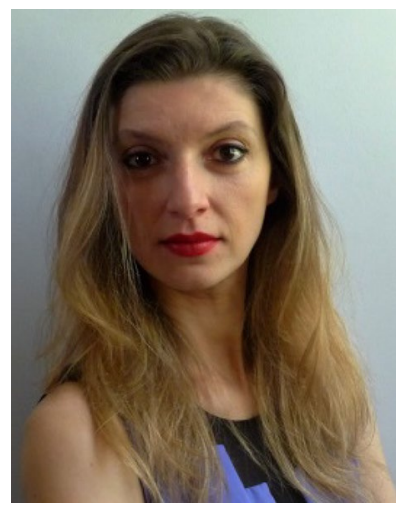

Melissa Tedone started her university career studying Marine Biology and Ecology at the University of Messina, where she completed B.Sc. and M.Sc. She was awarded a Ph.D. scholarship and, in March 2014, completed her Ph.D. in Food Chemistry and Safety from the SCIFAR Department, University of Messina. During this course, her research has been mainly focused on the analysis of aroma and flavour compounds through GC and GC $\times$ GC analysis in essential oils, food, beverages, and other kind of products. Furthermore, she has been involved in the characterization of fatty acids 
from different sources, such as plants and marine organisms, by monodimensional GC and GC $\times$ GC. Currently she is working on hop and beer chemistry as Postdoctoral Research Fellow at ACROSS, University of Tasmania. Her interests are focused in analytical chemistry applied to marine biology/ecology/microbiology and analyticalfood chemistry fields.

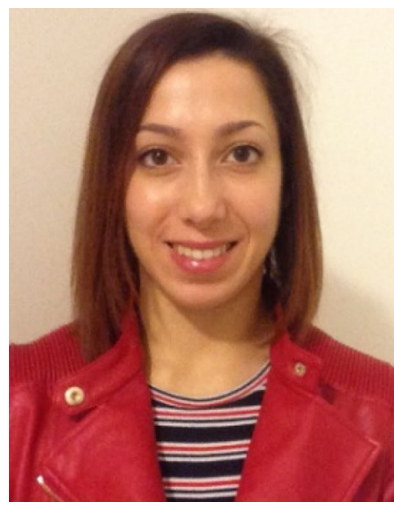

Sara Tengattini obtained her Ph.D. in Pharmaceutical Chemistry and Technology from the University of Pavia (Italy) in 2016, defending a thesis entailed "Development of innovative analytical methods for the characterization of potential neo-glycovaccines against tuberculosis", under the supervision of Gabriella Massolini. She spent part of her Ph.D. in the group of Govert W. Somsen at the Vrije Universiteit in Amsterdam (Netherlands). Since 2016, she has held a post-doc position in the Pharmaceutical Analysis Laboratory at the University of Pavia. Currently, her main interests lie in the development of novel chromatographic and MS-based approaches for the characterization and quality control of different biotechnological products, including glycopeptide antibiotics, recombinant therapeutic proteins and extracellular vesicles (EVs).

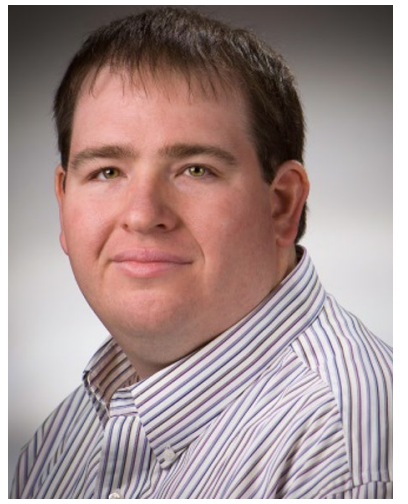

Walter Brent Wilson received his $\mathrm{Ph}$. D. in Analytical Chemistry from the University of Central Florida (UCF) in August 2014, under the direction of Andres D. Campiglia. His research involved the development of new methods for the extraction, separation, and spectroscopic detection of polycyclic aromatic compounds (PACs) in environmental samples. In April 2015, he was awarded the Outstanding Dissertation Award from the College of Sciences at UCF. Prior to attending UCF, he received a Bachelor of Science degree at Greensboro College and a Master of Science degree at the University of North Carolina of Greensboro. In February 2015, he was awarded a 2-year National Research Council post doctoral fellowship at the National Institute of Standards and Technology (NIST), Chemical Sciences Division, under the direction of
Stephen A. Wise and Lane C. Sander. His research focused on shape-selective separations of PACs using normal-phase and reversed-phase liquid chromatography. After completion of this fellowship, he joined the Organic Chemical Measurement Science Group at NIST as a research chemist. His current research deals with the certification of tobacco and natural products reference materials through the development of new chromatographic separation methods. He has published 29 publications in international peer-reviewed journals and has had over 50 presentations at multiple local, national, and international conferences. In 2018, he was elected as the vice president/program chair for the Washington Chromatography Discussion Group.

\section{References}

1. Russkamp P, Chromatographia (2017) 80:647. https://doi. org/10.1007/s10337-017-3299-x

2. Song H, Cabooter D, Chromatographia (2017) 80:651. https://doi. org/10.1007/s10337-016-3204-z

3. Astefanei A, Dapic I, Camenzuli M, Chromatographia (2017) 80:665. https://doi.org/10.1007/s10337-016-3168-z

4. Wouters S, Haddad PR, Eeltink S, Chromatographia (2017) 80:689. https://doi.org/10.1007/s10337-016-3184-z

5. Haidar Ahmad IA, Chromatographia (2017) 80:705. https://doi. org/10.1007/s10337-016-3225-7

6. Uliyanchenko E, Chromatographia (2017) 80:731. https://doi. org/10.1007/s10337-016-3193-y

7. De Martino M, Bencivenni G, Mazzanti A et al (2017) Chromatographia 80:751. https://doi.org/10.1007/s10337-016-3161-6

8. Lamotte S, Gruendling T, Loeb U et al (2017) Chromatographia 80:763. https://doi.org/10.1007/s10337-017-3300-8

9. Tyteca E, Bieber S, Letzel T et al (2017) Chromatographia 80:771. https://doi.org/10.1007/s10337-016-3127-8

10. Kresge GA, Wong JMT, De Pra M et al (2018) Chromatographia. https://doi.org/10.1007/s10337-018-3593-2***

11. Nováková L, Sejkorová M, Smolková K et al (2018) Chromatographia. https://doi.org/10.1007/s10337-018-3666-2

12. Vanderlinden K, Desmet G, Broeckhoven K, Chromatographia (2018) https://doi.org/10.1007/s10337-018-3622-1

13. Wilson WB, Wise SA, Sander LC, Chromatographia (2018) https ://doi.org/10.1007/s10337-018-3621-2

14. Maya F, Cabello P, Figuerola CA et al (2018) Chromatographia. https://doi.org/10.1007/s10337-018-3616-Z

15. Lebanov L, Tedone L, Kaykhaii M et al (2018) Chromatographia. https://doi.org/10.1007/s10337-018-3649-3

16. Lebanov L, Tedone L, Kaykhaii M et al (2018) Chromatographia. https://doi.org/10.1007/s10337-018-3651-9

17. Tengattini S, Chromatographia (2018) https://doi.org/10.1007/ s10337-018-3637-7

18. De Simone A, Naldi M, Bartolini M et al (2018) Chromatographia. https://doi.org/10.1007/s10337-018-3663-5

19. Salmean C, Dimartino S (2018) Chromatographia. https://doi. org/10.1007/s10337-018-3671-5

Publisher's Note Springer Nature remains neutral with regard to jurisdictional claims in published maps and institutional affiliations. 